\title{
THE CONCEPT OF SELF-EFFICACY AND SELF-EFFICACY-PERFORMANCE RELATIONSHIP
}

\author{
Derya Erel \\ Ankara Üniversitesi \\ Siyasal Bilgiler Fakultesi \\ Araştırma Gơrevlisi
}

\section{Öz-Etkililik Kavramı ve Öz-Etkililik-Başanm İlişkisi Özet}

Amerikan üniversitelerinde çokkültürcülük tartışmalarının konu edildiği bu yazıda, son dönem siyaset kuramında önemli bir yer edinmiş olan çokkültürcülük tarışmaları somut bir bağlam içinde değerlendirilmeye çalışlmıştur. Bu bağlamda ilk olarak, bu tartı̧̧manın üç temel ayağı olarak görülen, olumlu cylem politikası, çokkültürcü müfredat ve ifade kurallarıyla ilgili sorunun genel hatları çizilmiş; daha sonra bu tarışmalar surasında belirginleşen siyasi söylem ve konumlar analiz edilmiştir. Yazıda üniversite eğitimiyle ilgili olarak bu tartışma büyük ölçüde ırksal farkllıklar, yani siyah-beyaz sorunu çerçevesinde ele alınmıştır. Bu analizler ışığında geliştirilen yazının temel argümanları söyle özetlenebilir: Amerika'da sağ ile solu bölen son derece hassas bir siyasi tartışmaya dönüşen çokkültürcülük konusundaki siyasi saflaşmalar aslında liberal bütünleşme umutlarının tükenmesiyle ilgili derín toplumsal sorunlara işaret ctmektedir. Liberal bütünleşme umutlarının tükenişi siyah cemaati ve egemen düzen için farklı korkulan gündeme getirmekte ve karşılıklı zitlaşmayı artırmaktadır. Bu süreçte siyahlar giderek daha fazla dışlanma korkusuyla dolarak içe kapanma eğilimi gösterirken egemen düzen de neo-liberal korkular temelinde söylemsel saldınya geçerek onları daha da marjinalleştirmektedir.

\section{Abstract}

Self-Efficacy (SE) is the belief or perception of a person that he or she is capable to perform a specific task. It is a dynamic element that influences other concepts such as goals, performance and is influenced by them. SE is an essential clement in Social Cognitive Learning Theory. It plays a role of connecting goals, performance, and motivation concepts. It is one of the individual related concepts that function as a mediating mechanism among these concepts. Various research results show that SE may be a good predictor of performance. Since SE may be a good predictor of performance, managers may try to assess the SE of candidates to predict their potential performance, thus regulating their human resources practices such as selection, adjustment, manager development etc., according to that. In the two studies we have conducted, consistent with the results of previous research, moderatc positive comelations (Study 1: .449, Study 2: .388) are found between SE and performance for a simple memory task. 


\section{The Concept of Self-Efficacy and Self-Efficacy-Performance Relationship}

\section{Introduction and Objective}

In social psychology, Social Cognitive Theory accepts the interaction of self, environment and cognitive processes in understanding the relations among human beings and in discovering the causes of human behavior. Self-Efficacy (SE), which is a key element in Bandura's Social Cognitive Learning Theory, plays a role of connecting goals, performance, and motivation concepts. It is one of the individual related concepts which functions as a mediating mechanism among these concepts. SE is the belief or perception of a person that he or she is capable to perform a specific task (GIST, 1992; GIST, 1987; SANNA, 1994; BANDURA \& CERVONE, 1983).

$\mathrm{SE}$ is a dynamic element that influences other mechanisms such as goals, performance and is influenced by them. Locke called the linkages between these categories "hub", which means "a center of activity" (1991: 296). Individuals face many different combinations of influences over them in their daily lives. Their experiences with others, with their jobs, with all other aspects of the life, and the perceptions of these factors by them affect their attitudes and behaviors. In this dynamic process, SE functions as an element which is shaped by other factors, and which influences them.

The objective of this paper is to discuss the concept of SE and to show its relation to performance. In the paper, other relevant concepts of Social Cognitive Theory such as goals, and feedback are discussed as well. In the first section, SE is explained. Measurement, formation and boosting of SE are presented in subtitles to clarify its meaning. In the second section, SE-performance relationship is discussed by integrating goals and feedback mechanisms to the model. In the third section, practical meaning of SE is emphasized by giving its organization and information technology related implications. Finally, in the 
fourth section, two studies ${ }^{1}$ inspired by the work of Rebok, G.W., \& Balcerak, L.J. (1989) are conducted and the results are discussed.

One of the aims of this article is explaining the concept of SE. Thus, the article is partly an integrated literature review. The other aims are making a theoretical contribution ${ }^{2}$ to the field by testing the mediator role of SE for a simple task, comparing the results of current and previous studies and evaluating them. ${ }^{3}$ Some can see self-efficacy as a new version of expectation or self-esteem, and can call it "old wine with new labels" as done by Kirsch (1985). However, we interpret SE as a new mediator concept affecting goal-performance relationship.

\section{SE Concept}

\subsection{SE in General}

SE is a very central persuasive belief about people's capabilities that they can control their own level of functioning and events that affect their lives. Gradual acquisition of complex cognitive, social, and physical skills by the experience, creates $\mathrm{SE}$, and people's behaviors are regulated accordingly. $\mathrm{SE}$ is not concerned with individuals' skills, but with their perceptions of what they can do with their skills. SE has three main aspects that should be understood: First, SE is one's perceived capability to perform a specific task. Second, SE is a dynamic element because it changes over time. Finally, mobilization of efficacy beliefs affects performance. Thus, people with same skills may show different performance levels. Since it is a task specific concept, it is important to understand and measure SE for a specific task (GIST, 1992; GIST, 1987; BANDURA, 1991; MATHIEU, 1993).

Three dimensions of SE which are subject to measurement are (1) magnitude: Perceived attainable task difficulty, (2) strength: Strength or weakness of the conviction of magnitude, and (3) generality: Expectation's possibility of generalization across different situations (GIST, 1987).

1 First one in 1994 in the U.S.A. and the second one in 1999 in Turkey.

2 For a discussion of theory building and theoretical contribution, see:

* Academy of Management Reoiew (Forum on Theory Building), 14 (1989).

- Weick, K. E., "Theory Construction as Disciplined Imagination", 516-531.

- Whetten, D.A., "What Constitutes a Theoretical Contribution", 490-495.

"Administratioe Science Quarterly (Forum on Theory Building), 40 (1995).

- DiMaggio, P.J., "Comments on 'What Theory is Not' "', 391-397.

- Weick, K.E., "What Theory is Not, Theorizing Is", 385-390.

3 In order to protect the flow of the article, the context and method of some of the referred studies are explained in the footnotes. 
It may be beneficial to distinguish the meaning of SE from other self-concepts. Two related expectancies determine a person's motivation: SE and outcome expectancy. While SE is one's perception that he or she can perform in a specific task, outcome expectancy is the anticipation of external results. SE has a meaning broader than expectancy. It includes the expectation of the individual about the degree of effort. In addition, it includes the ability, adaptability, creativity and capacity to perform in a given situation. However, Kirsch argues that outcome expectancies are defined in two different ways. First, outcome expectancies mean "perceived environmental contingencies" or the belief that one reinforcer affects another one. Second meaning is people's beliefs about the consequences of their own behavior. In this second meaning, outcome expectancies are same as SE according to Kirsch (1987: 825). Self doubt is the opposite of SE, and is a kind of factor that inhibits self-regulated performance. Self-esteem is a trait. SE is a kind of task-specific self-esteem. Although some people see SE as a trait, by definition SE is task specific ${ }^{4}$ and narrower in scope than selfestecm. (SANNA, 1994; TUCKMAN, 1992; GIST, 1992; LOCKE, 1990; GARDNER et al., 1998).

Normally, future actions can not influence present situation. However, cognitive representation of future events in the present, results in future to influence present. When people value activities, they are interested in activities at which they judge themselves to be self-efficacious and they are satisfied mastering challenges. People's perceptions of their efficacy influence their anticipations and scenarios about the future. People who have high sense of SE anticipate success and think positively about their future. Those who have low sense of SE, anticipate failure. Pcople's beliefs in their efficacy influence their choices, their aspirations, mobilization of effort in a given endeavor, resistance to difficulties, amount of stress and vulnerability to depression. A strong sense of SE diminished negative thoughts and anxiety arousal. ${ }^{5}$ Low efficacious

4 Schwarzer argues that SE can be generalized. For a scale of the generalized version of SE (available in several languages) see: http://userpage.fu-berlin.de/health/sefscal.htm

Sec also: Jerusalem, M., Schwarzer, R. (1989), "Anxiety \& Self-Concept as Antecedents of Stress \& Coping: $\wedge$ Longitudinal Study with Cerman \& Turkish Adolescents", Personality and Social Differences, Vol. 10(7), 785-792.

5 Ozer et al. (1990) tested the hypotheses that perceived coping and control SE govern the effects of personal empowerment over physical threats. They have conducted an experiment to test their hypotheses, and predicted that the empowerment program by participating in a mastery-modeling program would enhance perceived SE to cope with problematic social situations and to control negative cognitions. The participants were 43 women ranged in age from 18 to 55 years. Thirty-eight percent of the participants had been assaulted at one time or another by a person. Participants mastered the physical skills to defend themselves against unarmed sexual assailants. Then, the effects of the empowerment program, by measuring the changes in relevant variables, were investigated. Results of this study showed that higher SE levels result in the diminishing of negative thinking and anxicty arousal 
people are victims of stress and depression. After SE is strengthened against threat, it no longer creates stress (BANDURA, 1989; BANDURA, 1991; OZER et al., 1990).

People's beliefs in their efficacy influence the perceived causes of success and failure. People with high SE tend to attribute failures to insufficient effort, whereas inefficacious people tend to attribute failures to low ability. People with high SE see difficult jobs as challenges. They have strong commitments and high level goals; they quickly recover their sense of efficacy; make things happen. People with low SE see difficult jobs as threats. They stay away form difficult jobs; they have low aspirations, weak commitments to the goals; they are pessimistic; give up quickly in the face of difficulties; they are slow to recover their sense of efficacy; they are victims of stress and depression; they are passive observers (BANDURA, 1991; BANDURA, 1989).

SE has also effects on thinking processes. Analytic thinking, anticipation, cognitive motivation are affected by SE. People who believe they have strong capabilities of problem solving (high SE in problem solving) are highly efficient in their analytic thinking in complex decision making situations. On the contrary, self-doubts are erratic in their analytic thinking (BANDURA, 1989). SE affects human mind in several ways (GIST et al., 1991): 6

- High SE creates more developed schemas for integrating performance relevant knowledge.

- By reducing anxiety, SE may facilitate retrieval process in the memory.

- SE creates stronger motivation to maintain learned skills

Perceived SE predicted memory performance when SE was measured in terms of subjects' evaluations of their highest memory capability (Bandura,

6 In their study, Gist et al. (1991) tested the following hypotheses:

- H1: SE will be positively related to performance on a complex interpersonal task (salary negotiations).

- H2: Trainees' initial SE will contribute positively to negotiation skill maintenance following 7-week time log.

- H3: Post-training design will interact with trainee SE to influence skill maintenance.

The study examined the effect of SE on the acquisition and maintenance of negotiation skills. The participants were 79 first and second year MBA students at a large state university in the USA. SE was the independent variable and negotiation performance was the dependent variable. Participants received 4 hours of basic training in salary negotiation. Then, they have completed a written assessment of their knowledge of learning content and SE measure. After that, trainees engaged in a negotiation session (Time 1). During the week following Time 1 negotiation, trainees were assigned randomly to one of two post-training workshops designed to enhance skill maintenance. 7 weeks after Time 1 negotiations, participants engaged in a second (Time 2) negotiation session and their SE and performance are measured again. Results of the study supported hypotheses $\mathrm{H1}, \mathrm{I1} 2, \mathrm{H} 3$. 
1989). In Rebok et al.'s study ${ }^{7}$, subjects who think their SE is low, were given a memory task of remembering 12 nouns in their exact order and were asked how many words they could recall. The results showed that the higher the SE was, the higher the memory performance was.

A memory task can be considered as a simple task. A limitation of the predictive validity of SE for performance can occur due to the quality of the task. Gist suggests that the predictive validity of SE for performance on complex tasks may be weaker than for performance on simple tasks. The reason proposed for that is that individuals expect their performance levels at a lower accuracy in complex tasks due to their inability to assess task requirements. Furthermore, insufficient individual or situational resources and/or constraints for these tasks affect individuals' expectations (1992).

\subsection{Formation and Boosting of SE}

There are three general intervention strategies suggested by Gist (1992) to enhance SE:

(1) Providing information about task

(2) Training individuals to improve their abilities

(3) Informing individuals to enhance their understanding about all of the factors, behaviors, strategies, and task performance.

However, for any training program, which aims at developing SE, initially, assessment of how SE changes and how it can be developed is required. For that, the antecedents of SE should be understood. The antecedents of efficacy development are classified in two groups. They are either internal or external. Examples of internal antecedents are knowledge, skill \& ability, personality factors, performance-related strategies. External category includes

7 Rebok et al.'s (1989) study was an effort to test the following hypotheses:

H1: Systematic age differences exist in the SE-memory performance relationship.

H2: SE perceptions can be improved through mnemonic training.

The subjects of the study (experiment) were 48 young adults (average age $=18.08$ years) and 45 old adults (60-78 years). The task was to memorize serial words and digits. In the study, there were eight experimental groups formed by crossing the two age groups with no training/ no feedback, training/no feedback, no training/feedback, training/feedback conditions. In order to assess subjects' SE, a SE scale was developed. The participants were asked to rate the strength of their expectation to recall 12 words and 12 digits in their exact order. Consistent with the findings of previous studies, Rebok et al.'s study provides support for the hypothesis that there are age differences in serial-recall performance and memory SE. However, there was no support for the second hypothesis. In other words, the mnemonic training did not reduce initial age related performance differences and the training did not increase SE. 
task attributes (difficulty, complexity), normative information (models, persuasion) (MATHIEU, 1993).

There is a difference between having some abilities and being able to use them. People tend to abandon their trained skills when they fail, if they are not convinced of their personal efficacy. This reality creates the need of training programs, which also tend to develop SE beyond developing other skills. SE may develop during training programs and it is an important mediator between individual \& situational antecedents and training outcomes (BANDURA, 1989; MATHIEU, 1993). ${ }^{8}$

There are four sources that affect the development of SE. First and the strongest is "enactive mastery", which means repeated performance accomplishments. In other words, enactive mastery is previous experiences in the same or similar situations. When they have positive results (successes), they increase SE. Second, "modeling" may be useful. Third is "verbal persuasion", which means convincing a person that he or she is capable to do something. Fourth, "physiological state or anxiety level" may enhance SE as does in the example of presentation anxiety (MATHIEU, 1993; GIST, 1987).

Among those cited above, the use of demonstration before the practice, or modeling is one of the commonly used instructional techniques to enhance SE. It was demonstrated that cognitive modeling training enhanced SE. Therefore, Social Learning Theory may be a basis for training design. Using the method of strengthening model-observer similarity, SE can be changed. A model perceived as similar by the performer is more likely to enhance the idea that the skill is achievable. Maximization of similarity occurs when individual serves as his own model (self-modeling). In self-modeling, individual observes himself in the videotape. Research results show that self-modeling contributed to the enhancement of SE. Gist \& Schwoerer concluded that watching a model perform a specific computer software operations (modeling) increases people's beliefs about their capabilities, and this positively affects performance (1989). Also, modeling training creates positive work styles, affects training process positively and increases trainees' satisfaction (GIST et al., 1989; GIST, 1989). ${ }^{9}$

8 Mathieu et al. (1993) agree with the categorization of individual attributes (knowledge, skill, abilities, performance related strategies, personality factors and mood states) and external categories (situational antecedents such as task difficulty, complexity, distractions, models, persuasion). They have tested the effects of SE on training outcomes. The training program was an eight week long introductory bowling course at Pennsylvania State University, USA. They have found that SE is a mediator construct between individual and situational antecedents and training outcomes.

9 - In Gist et al.'s 1989 study, one of the 6 hypotheses was as follows:

H1: Trainees in a behavioral modeling training program will exhibit better performance on an objective test of software mastery compared with trainees in a tutorial training program. 
There are some limitations of the efforts to boost SE. Self-modeling may not always be successful. Winfrey et al. explained two reasons for the failure of self-modeling to enhance $\mathrm{SE}$. One is the use of a single pre-experimental tape, which does not show any improvement to performers. Second is the intermediate skill level of the subjects (1993). ${ }^{10}$

Training efforts may give different results depending on the individual characteristics of the people. Initial level of SE, initial performance and achievement motivation, which is the desire to overcome obstacles to exercise power, and training choice (voluntarily) correlates positively with SE. The success for highly efficacious people in training is greater than those low in SE. For trainees low in pre-test SE, modeling training is better in terms of training performance. People with internal locus of control need less enactive mastery; they accept modeling because they think they are models. People with external locus of control see enactive mastery as luck. They may reject modeling because they do not think they have the skills of models. In this case, verbal persuasion may be useful (MATHIEU, 1993; GIST, 1989; GIST, 1987).

Situational constraints may have negative effects on SE. Research showed that when people believe they are in a situation they have little control, their

Participants were 108 managers at a large state university in the U.S.A. They were asked to enroll in a 3-hour training course in the use of a software package. Prior to training, their computer SE, which is an individual variable, was measured. The measures for task performance (dependent variable) were on the dimensions of affective response and working style. Research results supported the H1 hypothesis. Participants in modeling training achieved higher performance than participants in tutorial training did. Moreover, participants who took behavioral modeling training showed higher satisfaction with training than tutorial participants did.

- In Gist's 1989 study, a field experiment was developed and conducted. The hypotheses tested were as follows:

H1: Participants receiving cognitive modeling training will develop higher SE than participants who receive lecture training.

H2: Participants who receive cognitive modeling training will perform better on idea generation tasks than those who receive lecture training will.

The dependent variables were SE, and performance in the generation of ideas. Training method was the independent variable. Participants were 148 managers in a major federal agency in the USA. For the control group, a method of lecture/discussion with practice was employed. Two performance tasks involving the generation of ideas to improve quality in the organization and the generation of ideas for improving customer service were used. To measure SE, efficacy statements like, "I am capable of generating at least X ideas in 10 minutes for improving an aspect of this organization" were used. Results showed that the training involving cognitive modeling would be superior to that involving lecture for enhancing $S E$ and performance.

10 In Winfrey et al.s 1993 study, subjects were female gymnasts who were divided into two groups. One of the groups was a control group. The other group consisted of participants who watch self-modeling videotapes. The subjects in self-modeling group viewed the videotape of themselves three times a week prior to practice. Across a 6-week period, the study showed that there were no significant differences of SE between the group that experienced self-modeling and the group that did not. 
efficacy levels decreased. According to Mathieu, whatever the source of constraints (individual or environment), trainees reacted negatively against any limitations in their environment (1993). ${ }^{11}$

\subsection{Measurement of SE}

In Bandura's theory, measuring SE means measuring its three dimensions mentioned in part 1.1: Magnitude (the level of task difficulty a person believes he or she can perform), strength (confidence in attaining the various levels of magnitude), and generality (the applicability of efficacy experiences). First two dimensions are more likely to apply to organizational contexts (LUST, 1993).

In designing the model of measurement of $\mathrm{SE}$, various levels of graded series of performance are determined. Then, subjects were asked whether they believe they can attain these levels, and their confidence is measured. In this process, subjects answer questions about whether they can perform increasingly more difficult levels of a given task. No answers are scored zero; yes answers are scored one. Higher score at this magnitude scale means high SE. Strength is measured by asking subjects how confident they are. 0 to 10 or $0 \%$ to $100 \%$ scales are used (LATHAM, 1991; LUST, 1993). 1993):

There are three ways to measure SE when this format is used (LUST,

(1) Summing the strength responses for "yes" magnitude responses.

(2) Summing all strength responses

(3) Measuring only strength responses

There are other measurement methods of SE that are undifferentiated on task difficulty, and that use Likert-type items. In this case, subjects are presented with statements relating to the aspects of the task performance. Strongly agree to strongly disagree type Likert format is used in this kind of measurement. Only a general assessment of perceived SE is possible in this measurement (LUST, 1993).

Timing of measurement is also important. J.Kevin Ford et al. suggests the measurement of SE at the end of training, and before the assignment, in order to better understand the causal relationship between SE and other concepts (1992). Since SE is a dynamic element, it is better to measure SE judgements and actions

11 Mathieu et al. (1993), suggests that any constraint (situational or individual), obligation and pressure that employees face while attending a training program has negative influence on SE and training effectiveness. 
closely in time, because experiences may change the level or strength of perceived self competence (BOUFFARD, 1990).

Gross miscalculation of one's efficacy may create trouble. However, when the activity is not dangerous, optimism in self-appraisal is beneficial (BANDURA, 1989). The reason for that is that optimism means creating higher goals and scenarios and this may enhance performance motivation.

\section{SE Performance Relationship}

\subsection{Goals and SE}

SE may play an integrating mechanism role between the Goal Setting Theory and Social Learning Theory. It influences goal setting subfunction of self-regulation. Capable people with high SE choose higher goals and remain firmly committed to them. Since SE affects both goal commitment and personal goal level, it is an antecedent variable, which is motivational but also informational (LOCKE, 1984; WOFFORD, 1992; BANDURA, 1991). ${ }^{12}$

To establish personal goals, people can use normative information (external reference) or efficacy judgements (internal reference). These SE judgements affect choice of goal level through a direct effect on perceived performance capability (MATHIEU, 1993; WOFFORD, 1992). ${ }^{13}$ That is why Mathieu suggests that managers should first concentrate on developing SE to influence personal goals of new employees, and then, after individuals get experience on the job, making normative comparisons in order to influence their goals and to motivate them (1993).

$\mathrm{SE}$, assigned goals, ability, goal-performance relationship are better described in Latham's model. In this model assigned goals affect personal goals and personal goals affect performance. SE mediates in this process. Assigning goals influences SE positively because people who are assigned challenging goals or high goals develop confidence (LATHAM, 1991).

12 In Locke et al.'s 1984 study, subjects were 209 undergraduate students from an introductory management course. The task was giving uses for common objects. The task was explained, and subjects were then given a practice trial. Then, they were asked to fill out a SE scale. To measure performance, seven trial sessions were performed. The subjects were asked to indicate their own quantitative goal, and their goal-commitment was measured before and after each trial on a five point scale ranging from "definitely will try (tried) my hardest" to "definitely will (did) not try at all to reach my goal." Results showed that SE affects goal level. SE affects goal commitment as well, when the goal was self-set.

13 In their meta-analytical study, Wofford et al. (1992) investigated the results of the studies concerning the relationship of goal commitment-goal level and personality factors. In total, they obtained 143 results in 78 studies in 62 articles. The results showed that SE level affects personal goal level, but especially goal commitment. 
In Garland's cognitive meditation model, assigned goals (externally imposed standards), and task goals or personal goals (cognitive image of assigned goals) are distinguished. SE mediates the relation of personal goals or task goals with performance (EARLY, 1991).

In Eden's model, SE and goals are determined reciprocally and they are both influenced by trait expectancy, which is a generalized version of SE. People seek generally a balance among their perceptions. The differences among people's standards, goals and performance create self-dissatisfactions. Anticipated self-satisfactions and dissatisfactions influence the level of subsequent performance. Large negative discrepancies lower perceived SE, but increase self-dissatisfactions; smaller ones reduce self-dissatisfactions, but strengthen SE. High SE fosters goal commitment. On the contrary, reduced self-efficaciousness results in goal abandonment (LOCKE, 1990); EARLY, 1991; BANDURA, 1983). ${ }^{14}$ According to Bandura (1989), people who have high SE set higher goals for themselves and have higher commitments to these goals.

Antecedent variables, which affect personal goal level and goal commitment, are considered as components of a task script stored in memory. A script track results in goal achievement when it includes high goal commitment and the level of goal commitment depends partly on SE (WOFFORD, 1992).

SE does not always affect goals. The condition for expectancy, SE and ability to affect personal goal level is that individual must have an unambiguous task. Managers may increase the subordinates' commitment to their goals by choosing tasks in high difficulty but low complexity (WOFFORD, 1992), because a task low in complexity is probably unambiguous at the same time.

\subsection{Feedback and SE}

All of the self-mechanisms interact to motivate people. SE is activated to enhance motivation when feedback is present with goals (BANDURA, 1983). SE affect how people respond to feedback (LOCKE, 1990). Tuckman concluded that feedback influences performance with the mediation of SE (1992) ${ }^{15}$ Feedback

14 In Bandura' 1983 study, subjects were provided with feedback or a substandard performance. After that, some of them abandoned their goal as unattainable and were no longer self-dissatisfied with moderate progress.

15 In Tuckman et al.'s 1992 study, subjects were 159 prospective teachers in their junior and senior years. The task was to write test items based on information given in lectures and text, for ten weeks. Subjects were told that the top third scorers would receive two bonus points, middle thitd scorers would receive one bonus point, and low third scorers would receive no bonus. At the star of each week, their SE is measured. They categorized the participants according to their self-perceived competence level (SE) as low, middle and high. Results of the study showed that feedback is more helpful in enhancing the motivation to perform of low and middle SE level pcople. 
can enhance performance for people whose perceptions of SE are middle or low levels. For people with high SE on the other hand, feedback may result in the decrease of their performance, because they may adjust their performance to others' level (TUCKMAN, 1992).

Johnson distinguished two kinds of feedback that are related to performance and SE (1993): Learning oriented feedback and performance oriented feedback (outcome feedback). It was predicted that learning oriented feedback to be beneficial in some complex and uncertain task situations. Informational feedback (learning oriented feedback) contributes to the increase of self-confidence, thus, causing SE to increase performance. In the case of difficult goals for example, informational feedback provides information necessary to correct errors (TUCKMAN, 1992; GIST, 1987).

On the other hand, research results show that performance oriented feedback is better in terms of error compared to learning oriented feedback. Individuals with high SE will perform better in the performance oriented feedback condition (JOHNSON, 1993). The main reasons are that:

- Overconfidence of people that were unaware of their performance level results in the increase of errors

- The control over learning oriented feedback lessens individuals' intrinsic interest. ${ }^{16}$

Extrinsic-intrinsic feedback distinction proposed by Lee is a point that emphasizes the importance of intrinsic interest-feedback relationship; thus affecting SE and performance. Intrinsic feedback is an objective performance such as sales quota; extrinsic feedback comes from supervisors, other sales people and customers (1989).

\subsection{Performance Prediction}

In general, SE can affect performance in two ways. One directly, second indirectly by affecting first personal goal choice and commitment to assigned

16 In Jonhnson et al's study, a computerized simulation of the Space Shuttle's Remote Manipulation System (the laboratory study took place in Johnson Space Center, Houston, USA) was used to investigate the moderator role of SE over the effects of feedback type on performance. Subjects were 54 undergraduate students. Haif of them participated in learning oriented feedback and half in performance oriented feedback. The results were consistent with the findings of previous studies that suggest learning-oriented feedback is more beneficial than performance oriented feedback for complex tasks. However, results of the study showed that, for participants whose SE are high, performance was poorer in the learning-oriented feedback condition compared to the performance-oriented feedback condition. 
goals (LATHAM, 1991). In Locke's model, SE level affects performance with the mediating mechanisms such as effort, persistence, direction, task strategies (plans) (1990). In this model, SE and performance are reciprocally related (LOCKE, 1984).

In addition, SE mediates the relationship of other motivating concepts with performance. For example, the effect of satisfaction on performance is indirect rather than direct and exists only in the conditions that are challenging and accompanied by high SE. In other words, the level of motivation and performance are positively affected by challenging goals. When goal level is controlled, performance is a positive linear function of SE (LOCKE, 1990; BANDURA, 1989).

SE mediates the effects of causal attributions on motivation and performance attainment. This is called "attribution analysis of experience". People think and decide the causes of their experiences, and that affects their performance with the mediation of SE (BANDURA, 1991; GIST, 1992).

The magnitude of performance gains is determined by the level of self-dissatisfactions and perceived SE for goal attainment. SE-performance-effort relations work in a circular way. When people exceed their standards, they increase their $\mathrm{SE}$, they raise their standards, and they create ncw discrepancies. People's ways to establish a balance in these situations is to create social comparisons. The effect of social comparison on performance is mediated through its effects on SE beliefs (BANDURA, 1983; BANDURA, 1991).

People need information to anticipate their future capabilities. The activation of self-evaluative processes requires knowledge of performance level and personal standards. The performance level is past related, because SE is much more related to past performance than to future performance (BANDURA, 1983; LOCKE, 1984).

Differences between what people expect and do may have different effects. Discrepancies between personal standards and attainments may motivate or discourage people depending on their beliefs. The influence of anticipatory cognitive simulations affected by SE has different impacts on performance depending on how pessimistic or optimistic they are (BANDURA, 1991; BANDURA, 1989).

Traits influence efficacy-performance relationship as well. Type A's have generally higher performance on job because they set higher performance goals, work on various projects at a time, and have higher SE perceptions. Self-doubts who have low SE are easily dissuaded when they face obstacles and failures. Efficacious people, on the contrary, intensify their effort and persist until they succeed when they face the same situation (LEE, 1988; BANDURA, 1991). 
Some other interesting SE-performance relationships have been discovered in recent years for organizations. Lee et al. found that SE is related with both the quantitative and qualitative (behavioral) aspects of sales performance. They concluded that SE perceptions are predictors of performance only when performance is controlled by individual. For example, actual sales are more likely to be related with the income of consumers (1989). ${ }^{17}$ In this case, the individual does not control performance level. Gist et al. found that SE predicts performance not only for work-related tasks but also for interpersonal tasks such as salary negotiations (1991). In Sanna et al.'s 1994 study ${ }^{18}$, people in the high efficacy condition performed better when they evaluated themselves than they did not. In the low efficacy condition, self-evaluation participants performed worse than no self-evaluation participants did.

An interesting argument contradicting with the ones cited above is about the limits of the predictive capacity of SE. According to Gist, in some cases "SE could be too high, thus producing overconfidence and poor performance" (1987: 482). We argue that, in these cases it should be looked at the source of efficacy beliefs. If the high efficacy beliefs are based on experience and training, in other words if they are "objective", SE, even it is too high, may still be a good predictor of performance.

17 In Lee et al.'s study (1989), questionnaires were sent to a large Northeastern manufacturing corporation in the USA, employing 160 sales representatives. The response rate was 52 percent. In the questionnaire; type $\Lambda$ behavior pattern, $S E$, and performance were measured. As the main measure of type A behavior pattern, Matteson and Ivancevich's (1980) Individual Behavior Activity Profile was used. In order to measure SE, questionnaire items were constructed regarding people's judgements of how well they could meet their sales quotas and other performance behaviors. Performance rating consisted of performance quality, which was the supervisor's rating of each respondent on all the dimensions of their performance appraisal form, and performance quantity, which was sales as a percentage of overall sales quota attained for each of the respondents.

18 Sanna et al. (1994) conducted two experiments regarding the effect of self-evaluation on SE-performance relationship. Participants of the first experiment were 60 introductory psychology students. The task was to find and record a word somewhat related to three words in each set shown to the participants. The three stimulus words in each set were shown on a computer screen to the participants for one minute. In this experiment, a practice trial was used. The efficacy expectancies were manipulated by practice item difficulty and feedback. Difficult question set was used for the low efficacy condition participants. High efficacy condition participants were told that they had performed very well. Low efficacy condition participants were told that they had performed very poorly. Same process was repeated with the self-evaluation of actual performance. A method that lets participants to believe that no one on research team would know their performance was developed. In the second experiment, participants were 120 introductory psychology students. In this experiment, no practice trial was used. In addition, in the second experiment efficacy expectancies were not manipulated by practice item difficulty and feedback. It was expected that participants performing an easy task should develop high efficacy expectancies, whereas participants performing a difficult task should develop lower efficacy expectancies. 


\section{Implications for Organizations}

\subsection{Human Resources Practices}

There are several implications of the findings on SE in human resources management. Since SE may be a good predictor of performance, organizations may try to assess the SE of candidates. This method could be used in job interviews. Furthermore, after employing individuals, developing their self-assessment skills may make their SE expectations consistent with their abilities (GIST, 1987; EARLY, 1991).

It was found that the newcomers' levels of SE affected their socialization and adjustments in their new organization. Highly efficacious people define their roles different from low efficacious people do, because they believe they are competent. Contrarily, low efficacious pcople accept the definition of situations offered by others (JONES, 1986)..$^{19}$

Managerial competencies and lcadership qualities are related with SE concept as well, because perceived managerial competencics such as technical, conceptual and human relation competencies are generalized forms of SE (GIST, 1987).

SE is related to the training need of organizations. Stevens et al. (1997) argue that low SE individuals benefit most from training in organizations. Thus, they suggest that human resource professionals should develop their training programs to match employees' SE levels.

An important construct investigated in recent years is "taking charge" at work. Taking charge is related to responsibility, SE, and perceptions of top management openness. It is an employee behavior that goes beyond role expectations and it is argued that taking charge is not motivated by the same factors as traditional activities. (MORRISON et al., 1999). In their study aimed at

19 Jones (1986: 267) predicted that "... people with high levels of SE might be expected to define their new roles differently than those with low levels because of differing beliefs about their personal competencies. Consequently, newcomers with high SE may take proactive stances toward role performance in order demonstrate their abilities; alternatively, the socialization tactics used may not affect their subsequent role orientations. These newcomers will interpret new situations as they see fit." Jones tested the following hypothesis:

A newcomer's level of SE will moderate the effect of institutionalized tactics on role orientation. The study was a longitudinal study including two questionnaires. Respondents were successive annual graduation class MBA students (127 first year-73 second year) in a U.S. university. The study investigated the correlations between various socialization tactics and role orientations depending on the SE conditions of individuals. Results showed that for newcomers with higher $S E$, the correlation coefficients between role orientation and socialization tactics were significantly lower compared to low SE condition individuals. 
investigating factors that motivate employees to take charge, Morrison et al. (1999) found that employees with high SE would be more likely to take charge at work. ${ }^{20}$

The concept empowerment is closely related to SE. SE is one of the most important dimensions of empowerment. Consun et al. (1999 Feb.) found ${ }^{21}$ strong positive relationship between work environment (peer helping \& supportive customer relations) and dimensions of empowerment (meaningfulness, personal influence and SE).

\subsection{Technological SE}

Resistance to change is one of the important problems that organizations face in today's world. In the case of computers, this resistance is much more important, because computers have been getting gradually important. People's beliefs that they have no control over computers may be another explanation of the factors preventing computers from diffusing much more rapidly.

Recent studies investigated the rclation of $\mathrm{SE}$, computer use and performance. They showed the influence of self-concepts in the use of technologically developed products. Among these self concepts, perceived SE was found to be an important factor which determines individual's decision to use computers and other technologically advanced products (HILL et al., 1987). Gist \& Schwoerer found that high computer SE trainees achieve greater mastery than low computer SE trainees do (1989). In Harrison's study (1992) of computer anxiety scale, people in organizations showed three different attitudes: (1) negative feelings (2) positive feelings (3) lack of understanding. Negative attitudes correlate with the lack of understanding and explain 26 percent of the relationship. In this study, it is found that computer SE of people correlated negatively with high anxiety, negative attitudes, and lack of understanding and positively with confidence and positive attitudes (1992).

On the other hand, computer skill level is one of the important determinants of computer use. Computer anxiety, computer attitudes and computer skill are related. People who are at higher computer skill levels have positive attitudes towards computers and are not anxious about computers. Individuals who have lower computer levels have negative attitudes and anxiety towards computers (HARRISON, 1992).

20 They conducted a survey and obtained data from 275 white-collar employees (self-report \& coworker data).

21 They conducted a survey and gathered data from 292 service workers in 21 private clubs throughout the U.S. 
Perceived complexity of innovations requires spending much more effort for the people who will adopt them. Hill et al. investigated the relationship of people's expectations of being able to control computers (their computer SE) and their decision to use them by examining their behavioral intentions to enroll in computer related courses (1987). ${ }^{22}$ They found that experience alone does not directly affects adoption of computers. Direct experience reduces anxieties and changes SE and then SE change leads to technology adoption.

More recently, Compeau et al. (1999 June) conducted a research to test the influence of Computer SE on computer usage. They have found that SE explains a total of $18 \%$ of the variance in an individual's computer usage. ${ }^{23}$ Also, Minsky et al. (1999 April) investigated the role of individual differences in using e-mail. They concluded that high computer SE people would be more likely to use e-mail. ${ }^{24}$ Another study relevant to information technology usage is done by Hunton et al. (1997) to investigate the relationship of user participation in the development of information systems and SE. ${ }^{25}$ Study results indicate that users' a priori SE beliefs about their ability to contribute to the information systems development process are positively related to participation. Furthermore, they have argued that even in situations where user involvement is high, lower SE levels may inhibit people's desire to participate in information systems development activities.

22 Hill et al. (1987) conducted two studies. In the first study, they investigated the relationship between people's computer SE belief and their decision to use computers. In the second study, they investigated the role of previous experience with computers in the decision to adopt computer technology. They predicted and wanted to test the hypothesis that experience with computers alone is not likely directly influence people's decisions about computers or use of computers, unless computer efficacy beliefs have been affected. In study 1, a questionnaire was administered to a sample of 304 undergraduate students (157 female, 147 male). This questionnaire contained items that assess computer efficacy beliefs and items that measure behavioral intentions to purchase or use computers. In study 2, a questionnaire was administered to a sample of 133 women enrolled in undergraduate psychology courses. Questionnaire 2 included all of the questions in study 1. In addition, three questions designed to assess previous experience with computers were asked to the participants.

23 They have tested their model using longitudinal data gathered from 394 end users over a one-year interval. They have concluded that the adoption of new technologies is not just about convincing people of the benefits of a technology. They argue, consistent with the suggested methods to boost SE, that adoption process should also contain coaching, teaching, and encouraging individuals that they have the skills and confidence to use the new technology.

24 They delivered surveys to 163 faculty members in two colleges in a large state university in the U.S. E-mail was available to participants from a 6 months to over a year period. They have found that together with rational choice and social context, SE explained $37 \%$ of
the variance in e-mail use.

25 Hunton et al.'s field experiment took place over a 19-month time frame and involved 516 clerical level accounting subjects. 


\section{Studies Aimed at Investigating SE-Performance Relationship 26}

\subsection{Methods}

\section{STUDY 1:}

\section{Subjects}

The subjects were $23 \mathrm{MBA}$ class students invited to join to the study during fall 1994 semester, at a public university in the U.S.A.

\section{Task and Procedure}

The task was remembering twelve words 27 in their given order. First, some explanations and examples of words similar to that are used in the study had been given before the study was conducted. Then, six questions were asked to the subjects about their beliefs in their capabilities to fulfill different levels of a memory task (SE). After that, the twelve words were shown, and the subjects were allowed three minutes to memorize the words. Finally, subjects were asked to write as much word as they can in their exact order.

\section{Measures}

Based on Bandura's framework of the measures of SE, magnitude and strength were measured. The magnitude is about YES or NO answers, and the strength is about the certainty of a subject of a performance level. As the measure of $\mathrm{SE}$, the sum of the strength for YES answers is calculated.

Measures for performance were the total number of words remembered correctly in their correct order. Total points were 60 for both SE and performance.

\section{STUDY 2:}

\section{Subjects}

The subjects were 49 undergraduates (24 female, 25 male) from an introductory management course invited to join to the study during spring 1999 semester, in a public university in Turkey.

\section{Task and Procedure}

The task was remembering twelve words ${ }^{28}$ in their order. After some explanations and examples of words similar to that are used in the study had

26 Our Hypothesis is that:

- SE and performance level are correlated for a specific task (here memory task).

2712 Turkish words: tembel, kalem, soba, cetvel, tavla, cimri, zeki, masa, duvar, pencere, kitap, havlu.

28 The words (actually letter groups) used in the memory task had no meaning at all in any of the known languages to the author and were thought to give no specific advantage to any of the subjects in performing the task. 
been given on the answer sheet, six questions were asked to the subjects about their beliefs in their capabilities to fulfill different levels of memory task (SE). Then, the twelve words (letter groups) were shown, and the subjects were allowed three minutes to memorize the words. Finally, subjects were asked to write as much word as they can in their exact order.

\section{Measures}

Based on Bandura's framework of the measures of SE, magnitude and strength were measured. The magnitude is about YES or NO answers, and the strength is about the certainty of a subject of a performance level. As the measure of SE, the sum of the strength for YES answers is calculated.

Measures for performance were the total number of words remembered correctly in their correct order. Total points were 60 for both SE and performance.

\subsection{Results}

Results obtained from studies are summarized below:

\section{STUDY 1:}

Variables

1. Performance

2. Self-Efficacy

Mean

29.43

25.65

\section{STUDY 2:}

Variables

1. Performance

2. Self-Efficacy
Mean

43.44

33.57
SD

16.22

15.14

SD

11.81

13.33
Correlation

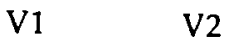

1

.449

.449

1

\begin{tabular}{ll}
\multicolumn{2}{c}{ Correlation } \\
V1 & V2 \\
1 & .388 \\
.388 & 1
\end{tabular}

Results show that SE and performance are moderately correlated. The value of the correlation coefficient is .449 in the first study and .388 in the second study. These relationships are statistically significant. ${ }^{29}$ From the results shown

29 - The $t$ value computed from our first study is 2.302 . The critical value of $t$ needed for statistical significance with 21 (23-2) degrees of freedom at .05 level (one-tailed), is 1.721 . Thus, since our computed $t$ value is bigger than 1.721 , we conclude that the relationship between $\mathrm{SE}$ and performance is statistically significant.

- The $t$ value computed from our second study is 2.88 . The critical value of $t$ needed for statistical significance with 47 (49-2) degrees of freedom at .05 level (one-tailed), is 1.678. Since our computed $t$ value is bigger than 1.678 , we conclude that the relationship between $\mathrm{SE}$ and performance is statistically significant. 
above we can conclude that, support was found for the positive relationship (moderate correlation) between SE and performance. In addition, the results supported the findings of the previous studies about SE-performance relationship. ${ }^{30}$

\subsection{Limitations of the Studies}

As cited above, the results of our studies are consistent with those of previous studies. However, the fact that a memory task is a relatively simple task may generate problems in terms of generalization. The correlation between $\mathrm{SE}$ and performance may be lower for complex tasks, due to the subjects' difficulties in correctly expecting their future performance levels for these kinds of tasks. In the future, further studies 31 investigating SE-performance relationship for different tasks with larger samples should be done to avoid generalization problems.

Another limitation may be about the effect of cultural and educational factors (individual level) for the task being chosen. For this reason, the task that is used is deliberately chosen to avoid the comparison problems. Consistent with the arguments of Early (1994) 32 , we argue that the chosen task (memory task) is minimally affected by cultural and educational level factors.

\section{Conclusion}

SE is one of the self-concepts playing an important role in the environment, cognitive, and behavior interaction process. It affects environment, behavior, and is affected by them. Until recent years; goal, performance, and feedback relations were believed to be direct, one sided. After the introduction of SE concept, it was shown that there are some mediating elements such as SE, which determines the level of influence between goals, performance, feedback etc. SE seems to have the capability to integrate Goal Setting Theory and Social Learning Theory.

The results of our two studies show that there is a moderate correlation between SE and performance for a simple memory task. Same relationship should be further tested for organization and management related tasks.

30 See for example, Locke et al. (1984), Taylor et al. (1984), Ford et al. (1992), Mathieu et al. (1992), Winfrey et al. (1993), and Sanna et al. (1994).

31 Stevens et al.'s (1997 Winter), Morrison et al's (1999 August), \& Cardner et al.'s (1998 March) studies are of this kind.

32 Early (1994) argues that SE is influenced by different sources of information. If these sources of information are affected by individual and cultural level factors, we need cultural and individual contingency approaches to investigate SE-performance relationship. 
Although it is a construct of social psychology, in recent years, scholars at business schools all over the world tend to do a lot of research about SE, because it has many application opportunities for organizational settings. Research results show that $\mathrm{SE}$ is crucial in understanding the motivational processes in organizations. Since the theory of SE exists but implications are limited, SE may have much more influence in the analysis of organizations in the future.

\section{References}

BANDURA, A. / CERVONE, D. (1983). "Self-Evaluetive and Self-Efficacy Mechanisms Governing the Motivational Effects of Goal Systems, - Jurnal of Personality $\mathcal{E}$ Social Psychology, 45: $1017 \cdot 1028$.

BANDURA, A. (1989), "Regulation of Cognitive Processes Through Perceived Self Efficacy." Developmental Psychology, 25: 729-735.

BANDURA, A. (1991), "Social Cognitive Theory of Self-Regulation. Special Issue: Theories of Cognitive Self-Regulation," Organizational Behavior E Human Decision Processes, 50: 248-287.

BOUFFARD-BOUCHARD, T. (1990), "Influence of Self-Efficacy on Performance in a Cognitive Task," Joumal of Social Psychology. 130: 353.363.

COMPEAU. D. / HIGGINS C.A. / HUFF. S. (1999 June). "Social Cognitive Theory $\varepsilon$ Individual Reactions to Computing Technology: A Longitudinal Study." MIS Quarterly, 23(2): 145-158.

CORSUN, D.L. / ENZ, C.A. (1999 February), 'Predicting Psychological Empowerment Among Service Workers: The effect of Support Based Relationships." Human Relations, 52(2): 205-224.

EARLEY. P.C.. E Litucy, T.P. (1991), "Delineating Goal and Efficacy Effects: A Test of Three Models," Joumal of Applied Psychology. 76: 81.99.

EARLEY, P.C. (1994 March). "Self or Group? Cultural Effects of Training on SE $\varepsilon$ Performance," Administrative Science Quarterly. 39 (1): $89 \cdot 117$.

FORD, J.K. / QUINONES, M.A. / SEGO. D.J. / SORRA. J.S. (1992). "Factors Affecting the Opportunity to Periorm Trained Tasks on the Job." Personnel Psychology. 45: 511 1.528.

GARDNER, D.G. / PlERCE, J.L. (1998 March), "Self-esteem $\varepsilon$ Self.efficacy within the Organizational Context: An Empirical Examination," Group \& Organization Management, 23(1): 48-70.

GIST, M.E. (1987), "Self-Efficacy: Implications for Organizational Behavior and Human Resource Management." Academy of Management Review. 12: 472.486.

GIST. M.E. / SCHWORER. C. / ROSEN. B. (1989). "Effects of Alternative Training Methods on Self-Efficacy and Performance in Computer Software Training." Joumal of Applied Psychology, 74: 884.892.

GIST, M.E. (1989). "The Influence of Training on Self-Efficacy and Idea Generation Among Managers," Personnel Psychology. 42: 787-806.

GIST. M.E. / STEVENS, C.K. / BAVETTA. A.G. (1991). "Effects of Self-Efficacy and Post Training Intervention on the Acquisition and Maintenance of Complex Interpersonal Skills," Personnel Psychology. 44:837.859.

GIST, M.E. / MITCHELL, T.R. (1992), "Self-Efficacy: A Theoretical Analysis of Its Determinants and Malleability. Academy of Management Review. 17: 183-212.

HARRISON. A.W. / RAINER, R.K. (1992). "An Examination of the Factor Structures and Concurrent Validates for the Computer Attitude Scale, the Computer Anxiety Rating Scale, and the Computer-Self-Efficacy Scale." Educational \&, Psychological Measurement. 52: 735-745. 
HILL, T. / SMITH. N.D. / MANN, M.F. (1987), "Role of Efficacy Expectations In Predicting the Decision to Use Advanced Technologies: The Case of Computers." Joumal of Applied Psychology. 72: 307-31 3.

JERUSALEM. M. / SCHWARZER, R. (1989), "Anxiety $\varepsilon$ Self-Concept as Antecedents of Stress $\varepsilon$ Coping: A Longitudinal Study with German $\varepsilon$ Turkish Adolescents," Personality and Social Differences, 10 (7): 785-792.

HUNTON, J.E. / BEELER, J.D. (1997 December), "Effects of User Porticlpation In Systems Development: A Longitudinal Feld Experiment," MIS Quanerly, 21(4): 359-388.

JOHNSON, D.S. / PERLOW, R. / PIEPER, K.F. (1993), 'Differences in Task Performance as a Function of Type of Feedbeck: Leaming-Orlented Versus Performance-Oriented Feedback," bumal of Applied Social Psychology. 23: 303.320.

JONES, G.R. (1986), "Socialization Tactlcs, Self-Efficacy, and Newcomers' Adjustments to Organizations," Academy of Management Joumal, 29: 262-280.

KIRSCH, I. (1985), "Self-Efficacy and Expectancy: Old Wine with New Labels," Joumal of Personality $\mathcal{E}$ Social Psychology. 49: 824.830.

LATHAM, G.P. / WINTERS, D.C. / LOCKE. E.A. (1994), "Cognitive and Motivational Effects of Participation: A Mediator Study," Joumal of Onganizational Behavior. 15:46.63.

LATHAM. G.P. / LOCKE, E.A. (1991), "Self Regulation through Goal Setting." Organizational Behavior $\mathcal{E}$ Human Decision Processes, 50: 212.247.

LEE, C. / EARLEY, P.C. / HANSON, L.A. (1988), "Are Type A's Better Performers?," Joumal of Organizational Behavior, 9: 263-269.

LEE, C. / GILLEN. D.J. (1989), "Relationshlp of Type A Behavior Pattern. Self Efficacy Perceptions on Sales Performance," Joumal of Organizational Behavior, 10: 75.82.

LOCKE, E.A. / FREDERICK, E. / LEE, C. / BOBKO. P. (1984). "Effect of Self-Efficacy. Goals, and Task Strategies on Task Performance." Joumal of Applied Psychology. 69: 241 -251.

LOCKE, E.A. / LATHAM. G.P. (1990). "Work Motivation and Satisfaction: Light at the And of the Tunnel," Psychological Science, 1: 240-246.

LOCKE. E.A. (1991). "The Motivotion Sequence, the Motivation Hub. and the Motivation Core. Speclal Issue: Theories of Cognitive Self-Regulation." Organizational Behavior E Human Decision Processes. 50: 288.299 .

LUST, J. A. 6 CELUCH, K.G. / SHOWERS, L.S. (1993). "A Note on Issues Conceming the Measurement of Self-Efficacy," burnal of Applied Social Psychology. 23: 1426-1434.

MATHIEU, J.E. / BUTTON. S.B. (1992). "An Examination of the Relative Impact of Normative Information and Self.Efficacy on Personal Goals and Performance over Time." Joumal of Applied Social Psychology. 22: 1758-1775.

MATHIEU, J.E. / MARTINEAU, J. W. / TANNENBACIM. S.I. (1993). "Individual and Situational Influences on the Development of Self-Efficocy: Implications for Training Effectiveness," Persorvel Psychology. 46: 125.147.

MINSKY, B.D. / MARIN, D.B. (1999 April). "Why Faculty members Use E-mail: The role of Individual Differences in Channel Choice." Joumal of Business Communication. 36(2): 194-217.

MORRISON. E.W. / PHELPS, C.C. (1999 August). 'Toking Charge at Work: Extrarole Efforts to lnitlate Workplace Change," Academy of Management Joumal, 42(4): 403.419.

OZER, E.M. / BANDURA, A. (1990), Mechanisms Goveming Empowerment Effects: A Self-Efficacy Analysis," Joumal of Personality $E$ Social Psychology, 58: 472-486.

REBOK, G.W. ) BALCERAK, L.J. (1989). "Memory Self-Efficacy and Performance Differences in Young and Old Adults," Developmental Psychology. 25: 714.721. 
SANNA, L.J. / PUSECKER, P.A. (1994). "Self-Efficacy, Valence of Self-Evaluation, ond Performance," Personality E Social Psychology Bulletin, 20: 82.92.

STEVENS, C.K. / GIST, M.E. (3997 Winter). "Effects of SE and Goal-orientation on Training and Negotjation Skill Maintenance: What Are The Mechanlsms?.' Personnel Psychology. 50(4): 955-978.

TAKLOR, M.S. / LOCKE, E.A. / LEE. C. / GIST. M. (1984). "Type A Behovior and Faculty Research Productivity: What Are the Mechanisms?," Organizational Behavior and Human Performance, 34: 402.418.

TUCKMAN, B.W. / SEXTON, T.L (1992). "The Effects of Informatlonal Feedback and Self-Beliefs on the Motivation to Pefform a Self-Regulated Task," burnal of Research in Personality. 26: 121-127.

WINFREY, M.L. / WEEKS, D.L (1993). 'Effects of Self-Modeling on Self-Efficacy and Balance Beam Performance," Perceptual E Motor Skills, 77: 907.913.

WOFFORD, J.C. / GOODWIN. V.L. / PREMACK, S. (1992). "Meta-Analysis of the Antecedents of Personal Goal Level and of the Antecedents and Consequences of Goal Commitment," Joumal of Management, 18: 595.615. 